\title{
IMPACTS OF URBAN EVOLUTION ON BIODIVERSITY CONSIDERING THE SUSTAINABLE DEVELOPMENT OF THE ECOSYSTEM
}

\author{
DONG, X. M. ${ }^{12^{*}}-\mathrm{XU}, \mathrm{S} . \mathrm{N}^{1}{ }^{1}$ \\ ${ }^{1}$ School of Architecture, Harbin Institute of Technology; Key Laboratory of Cold Region Urban \\ and Rural Human Settlement Environment Science and Technology, Ministry of Industry and \\ Information Technology, Harbin 150000, China \\ ${ }^{2}$ School of Architecture, Inner Mongolia University of Technology, Hohhot 010051, China \\ *Corresponding author \\ e-mail: 57126970@qq.com \\ (Received $7^{\text {th }}$ Jun 2019; accepted $10^{\text {th }}$ Oct 2019)
}

\begin{abstract}
The life of urban residents demands sufficient material supply and a good eco-environment. The rapid expansion of cities has stimulated the urban population and economy, exerting irreversible changes on the eco-system. During the urban evolution, it is of great importance to evaluate the overall impacts of urban development on biodiversity. The evaluation aims to integrate biodiversity protection into urban development and maintain it in a harmonious and stable state. Focusing on ecosystem sustainability, this paper designs the architecture to evaluate the impacts of urban evolution on plant diversity, and creates an integrated evaluation system for biodiversity from five perspectives, namely, species richness, species diversity, species evenness, species importance and population diversity. On this basis, the proposed system was applied to assess the biodiversity in a city. The assessment results show that continuous biodiversity evaluations can ensure the sustainable development of species during urban evolution. The research findings provide new insights into the diversity and sustainability of urban species.
\end{abstract}

Keywords: urban evolution, ecosystem, biodiversity, sustainable development, structure of plant community

\section{Introduction}

In recent years, following the rapid advancement of urbanization, human society has been facing unprecedented problems such as environmental damage, increased pollution, over-exploitation of resources, reduction of green spaces, and shortage of water resources, which urgently require the protection of the diversity of the city and improvement of the city's ecological environment while promoting the living standards of human beings (Olofson et al., 2009). Also, with the current urban development, the biodiversity and ecological stability are seriously threatened. Therefore, the issues of protecting the environment, rationally utilizing biological resources, and ensuring the biodiversity for sustainable development have gradually attracted people's attention (Hunter and Philip, 2007; Karmaker et al., 2018).

Multi-level, sustainable and stable use of ecological resources is an important part of biodiversity protection (Kaushal et al., 2014). With the acceleration of urban evolution, the natural appearance has also undergone great changes. In particular, the destruction of ecosystems has greatly affected the living space of biological species, seriously threatening the biodiversity closely related to urban ecological environment and human settlements (Crawford and Goldstein, 2010). Therefore, it's of great significance to protect the biodiversity for ecological cities in development, continuously improving 
ecosystems, and the overall level of urban construction, and achieving sustainable urban development.

Over the years, during the process of urban development, the rural population has gradually moved into the city, increasing the urban population rapidly (Loreau, 2001), which resulted in the excessive exploitation and utilization of various biological resources, and the continuous destruction of the soil and microbial environment, and even pushed some species to the verge of extinction. All these have further challenged the diversity of protected organisms (Lavorel, 2002; Reiss et al., 2009). Therefore, it is necessary to carry out a comprehensive evaluation study on the impact of urban development on biodiversity in the process of urban evolution, which not only enables the public to obtain effective information on the impact of urban development on biodiversity, but also makes the government departments to well realize the top-priority biodiversity indicators in the decision-making process of urban development (Miki, 2009).

As more emphasis is gradually put on ecological environment and biodiversity conservation in China, research results on biodiversity conservation have been also becoming more abundant (Tscharntke et al., 2005). But the research on the impact of urban evolution on biodiversity is still in the exploratory stage (Weiland et al., 2008; Lubbe et al., 2012). In order to develop the city and urban ecosystems sustainably together, it is necessary to ensure the biodiversity and the harmony of the ecological environment (Anstead et al., 2003; Burd et al., 2006).

As above, this paper constructs a comprehensive evaluation system of biodiversity based on urban evolution in order to understand the relationship between biodiversity and urban development. Then, taking the evaluation of a city as an example, it proposes relevant measures to further improve biodiversity. The research results indicate that during the urban evolution, a comprehensive evaluation considering the impacts of biodiversity is feasible for the conservation and sustainable development of biodiversity.

\section{Materials and methods}

The green space types of urban vegetation include residential green space, ecological landscape green space and public green space (Symstad et al., 2003). In order to study the impact of urban evolution on plant diversity, an evaluation system considering the impact of urban evolution on plant diversity was established (Fig. 1).

\section{Evaluation index of species diversity}

The index of species diversity mainly includes species richness, diversity, evenness, importance and population diversity (Gamfeldt et al., 2006), as shown below.

\section{(1) Richness index}

$$
R=\frac{S-1}{\ln N}
$$

where $\mathrm{S}$ and $\mathrm{N}$ respectively, indicate the number of species and the number of individuals. 


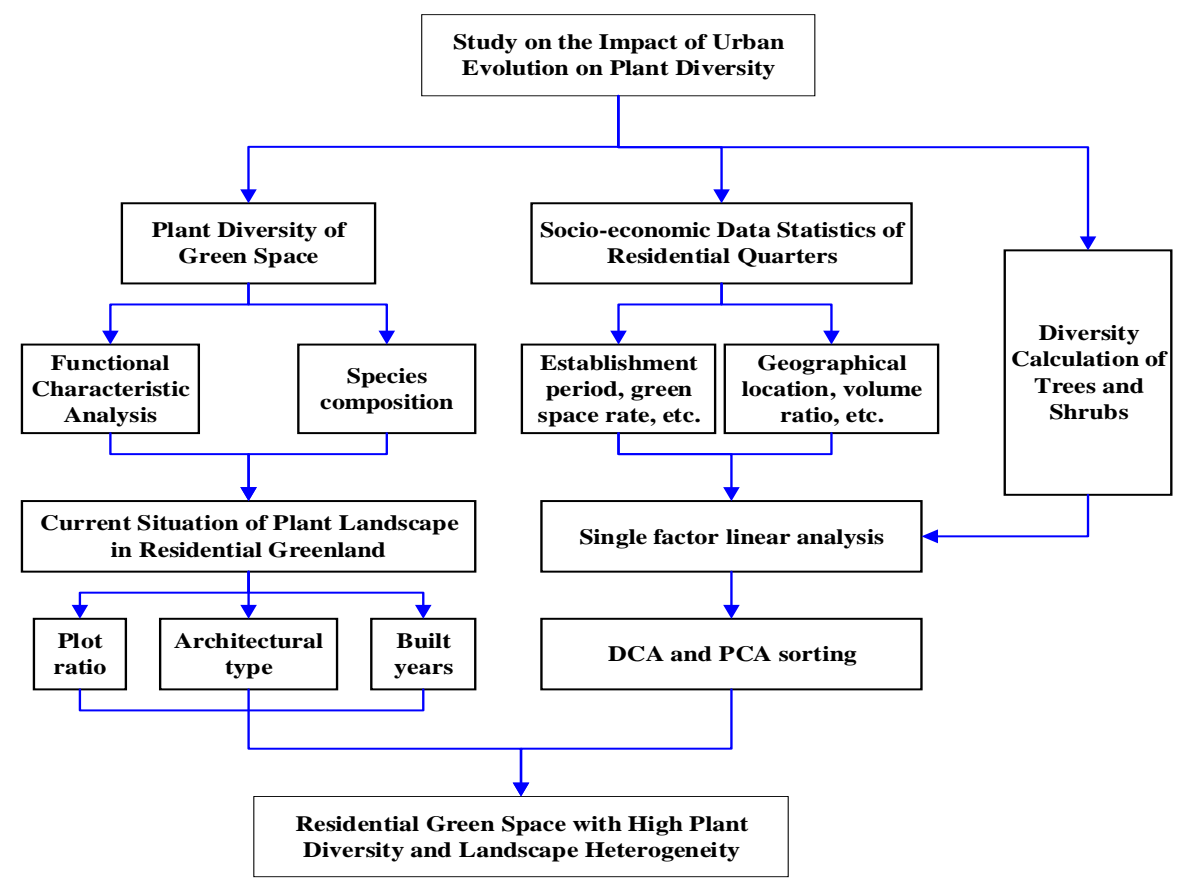

Figure 1. Evaluation system considering the impact of urban evolution on plant diversity

(2) Diversity index

$$
\begin{gathered}
H=-\sum_{i=1}^{S} P_{i} \ln P_{i} \\
D=1-\sum_{i=1}^{S} P_{i}^{2}
\end{gathered}
$$

where H, D respectively, refers to the Shannon-Wiener index and Simpson index; $N_{i}$ is the number of individuals for the $i$-th species, and $P_{i}$ is the proportion of the species.

(3) Evenness index

$$
J=\frac{H}{\ln S}
$$

$\mathrm{J}$ is Pielou index.

(4) Importance index

$$
I_{i}=\frac{\left(D R_{i}+F R_{i}+C R_{i}\right)}{3}
$$

where $D R_{i}, F R_{i}$, and $C R_{i}$ are the relative density, relative frequency, and relative coverage of the ${ }^{i}$-th plant respectively. 


\section{(5) Population diversity index}

It is divided into arbors, shrubs, and herbs. The population diversity refers to the average diversity of the three plants.

$$
D=\frac{W_{1} D_{1}+W_{2} D_{2}+W_{3} D_{3}}{3}
$$

In Equation 6, $D_{1}, D_{2}$, and $D_{3}$ respectively refer to the diversity index of the arbor, shrub, and herb; $W_{1}, W_{2}, W_{3}$ are the weight coefficient corresponding to the three plants.

\section{An integrated evaluation system of plant diversity}

In order to objectively and comprehensively evaluate the impact of plant diversity in urban evolution, it is necessary to build the evaluation index from the three aspects of species such as the biological characteristics (ornamental value, anti-pollution, pestresistance, etc.), ecological properties (light tolerance, drought tolerance, cold endurance etc.), combined greening effects (humidification, bactericidal, cooling, air purification, etc.) (Breton et al., 2007; Sun and Xu, 2010), as shown in Figure 2.

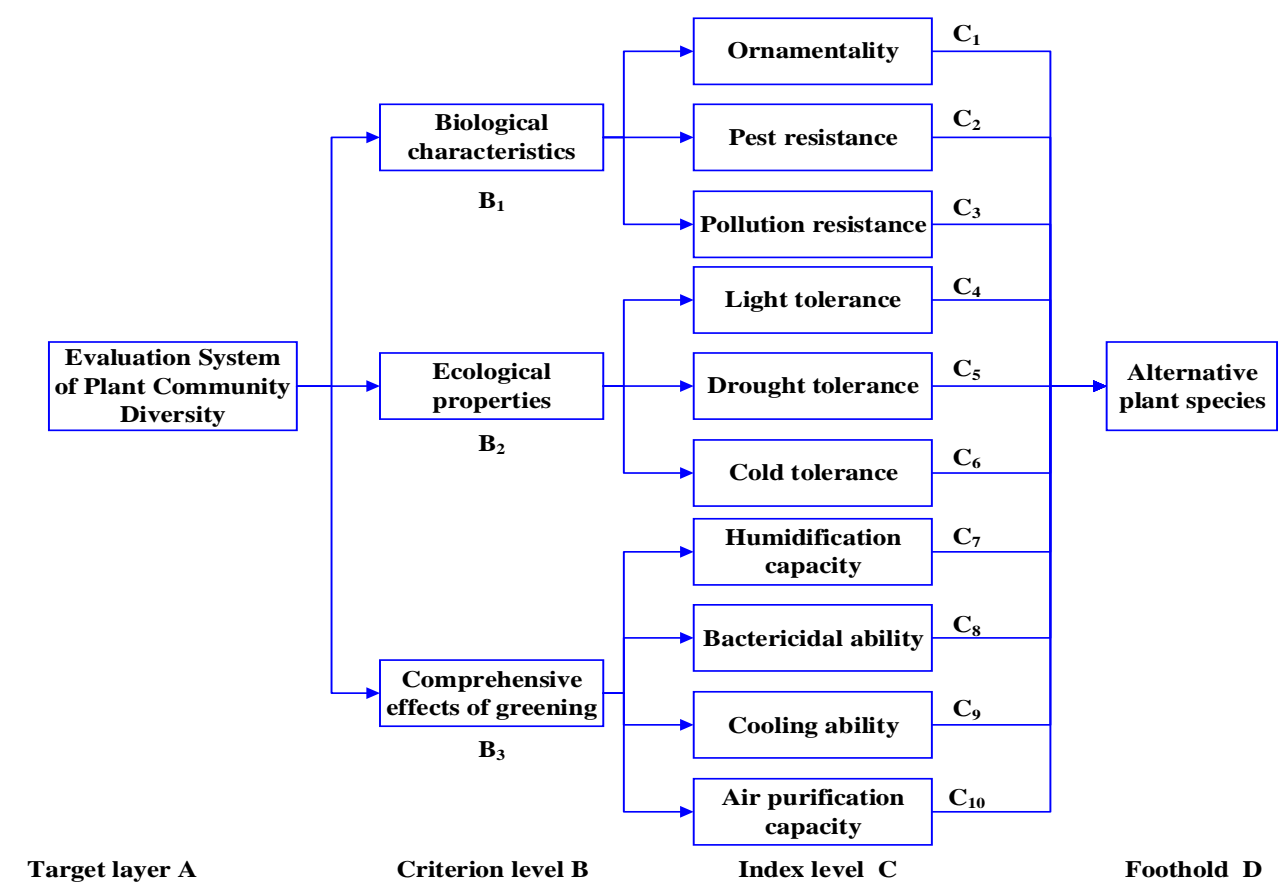

Figure 2. Evaluation system of plant diversity

\section{Determination of index weights}

Analytic hierarchy process (AHP) was adopted to construct the judgment matrix. Let

$$
a_{j i}=1 / a_{i j}\left(a_{i j}>0\right)
$$

Use 1-9 and its reciprocal as the scale to determine the value of $a_{i j}$. The composition of the Judgement Matrix (JM) is shown in the Equation 8 below. 


$$
J M=\left(\begin{array}{ccccc}
A & B_{1} & B_{2} & \ldots & B_{n} \\
B_{1} & c_{11} & c_{12} & \ldots & c_{1 n} \\
B_{2} & c_{21} & c_{22} & \ldots & c_{2 n} \\
\vdots & \vdots & \vdots & \ddots & \vdots \\
B_{n} & c_{n 1} & c_{n 2} & \ldots & c_{n n}
\end{array}\right)
$$

Further, the square root method was used to solve the weights of each index, and the consistency test was performed. The single-layer consistency test is shown in Equations 9 and 10, and the comprehensive consistency test is shown in Equation 11.

$$
\begin{gathered}
C I=\frac{\left(\lambda_{\max }-N\right)}{N-1} \\
C R=C I / R I \\
C R=\frac{\sum_{j=1}^{m} C I_{j} c_{j}}{\sum_{j=1}^{m} C R_{j} c_{j}}
\end{gathered}
$$

where $\lambda_{\max }$ is the largest eigenvalue of $J M, C I$ is the consistency indicator, and $C R$ is the consistency test indicator.

\section{Results}

Taking the centre of Nanning as the sampling origin, a grid with a spacing of $1 \mathrm{~km}$ was adopted, and the intersection point was the sampling point for analysis of urban green space and plant diversity. Nanning City is located in the southwest of Guangxi Zhuang Autonomous Region, about $50 \mathrm{~km}$ south of the Tropic of Cancer, and in the transitional zone from south subtropics to northern tropics. It belongs to the south subtropical monsoon climate. Its geographical coordinates are at $22^{\circ} 40^{\prime}-23^{\circ} 06^{\prime}$ north latitude, and $107^{\circ} 45^{\prime}-108^{\circ} 27^{\prime}$ east longitude. Facing Southeast Asia, it is backed by the southwest, bordering Hong Kong, Macao, and Hainan in the east, and Indian Peninsula in the west. It is the junction of the two major economic zones of the South China coastal region and the southwestern coastal region, and the connecting point of the Southeast Asian economic circle.

Through the comprehensive survey of selected survey sites, the representative plant communities in the survey sites were selected, and the $10 \mathrm{~m} \times 10 \mathrm{~m}$ samples were prepared respectively using typical sampling methods. The survey was conducted on January $1^{\text {st }}$ to December $31^{\text {st }}, 2018$ in six types of green spaces such as the comprehensive park, theme park, roadside green space, residential green space, public facilities green space, and road green space: the survey sites of the comprehensive parks include People's Park, Binjiang Leisure Park and Nanhu Park, with 14 sampling points; those of theme parks include Nanning Zoo and Guangxi Medicinal Botanical Garden, with 19 sampling points; those of roadside green space include Nanhu Square and Chaoyang Square, with 17 sampling points; those for residential green space include 
Beihu Anju Community, Cuihu New City, Hengda New City, Mingxiu Community, and Zhenning Cuifeng community, with 18 sampling points; those of public facilities green space include Guangxi University, Guangxi Sports General Administration, Nanning Theater, tand he First Affiliated Hospital of Guangxi Medical University, with 13 sampling points; those of road green space include Minzu Avenue, Zhonghua Road, Chaoyang Road, and University Road, with 9 sampling points. According to statistics, there were 90 effective sampling points and 476 plant species, including 127 genera and 349 species. Table 1 lists the specific composition. Table 2 shows the ratios of population to vegetation land in the urban, suburban, and remote suburbs.

Table 1. Composition of plant species at sampling points

\begin{tabular}{|c|c|c|c|c|c|c|c|}
\hline \multirow{2}{*}{\multicolumn{2}{|c|}{ Classification }} & \multicolumn{2}{|c|}{ Section } & \multicolumn{2}{|c|}{ Genus } & \multicolumn{2}{|c|}{ Species } \\
\hline & & Quantity & Proportion & Quantity & Proportion & Quantity & Proportion \\
\hline & Fern & 10 & $7.9 \%$ & 9 & $2.6 \%$ & 19 & $4.0 \%$ \\
\hline & Gymnosperm & 10 & $7.9 \%$ & 10 & $2.9 \%$ & 20 & $4.2 \%$ \\
\hline \multirow{3}{*}{ Plant } & Monocotyledons & 85 & $66.9 \%$ & 233 & 318 & $66.8 \%$ & $65.6 \%$ \\
\hline & Dicotyledons & 22 & $17.3 \%$ & 97 & 119 & $25.0 \%$ & $28.1 \%$ \\
\hline & Subtotal & 107 & $84.3 \%$ & 330 & 437 & $91.8 \%$ & $93.7 \%$ \\
\hline \multicolumn{2}{|r|}{ Total } & 127 & $100 \%$ & 349 & $100 \%$ & 476 & $100 \%$ \\
\hline
\end{tabular}

Table 2. Proportion of population and vegetation land in urban, suburban and remote suburbs

\begin{tabular}{c|c|c|c|c}
\hline Region & Area & Population density & $\begin{array}{c}\text { Population growth rate } \\
(\mathbf{\%}, \mathbf{2 0 0 0} \mathbf{2 0 1 8})\end{array}$ & $\begin{array}{c}\text { Proportion of vegetation } \\
\text { land }\end{array}$ \\
\hline Urban & 1405 & 5321 & 76 & 63 \\
Suburban & 3581 & 764 & 65 & 27 \\
Outer suburbs & 9860 & 213 & 38 & 11 \\
\hline
\end{tabular}

Through the judgment matrix, the weights of biological characteristics, ecological performance and greening effects were derived as $\mathrm{W}=(0.32,0.22,0.46) .5$ experts with a certain reputation in the industry were selected to score the above 10 indicators using 10-points system, and obtain the weights of each indicator (Table 3). The consistency test results are shown in Table 4.

Table 3. Index weights

\begin{tabular}{c|c|c|c|c|c|c|c|c|c|c}
\hline Index & $C_{1}$ & $C_{2}$ & $C_{3}$ & $C_{4}$ & $C_{5}$ & $C_{6}$ & $C_{7}$ & $C_{8}$ & $C_{9}$ & $C_{10}$ \\
\hline Weight & 0.127 & 0.112 & 0.081 & 0.037 & 0.117 & 0.066 & 0.113 & 0.145 & 0.076 & 0.126 \\
\hline
\end{tabular}

Table 4. Consistency test of indicators

\begin{tabular}{c|c|c|c}
\hline Consistency test & A-B & $\mathbf{B}_{\mathbf{1}}-\mathbf{C}$ & $\mathbf{B}_{\mathbf{2}}-\mathbf{C}$ \\
\hline$\lambda_{\max }$ & 3.0195 & 4.0445 & 3.0105 \\
$C I$ & 0.0107 & 0.0157 & 0.0067 \\
$R I$ & 0.5815 & 0.9015 & 0.5815 \\
$C R$ & 0.0177 & 0.0177 & 0.0097 \\
\hline
\end{tabular}


At these sampling points, the top 10 vegetations in terms of importance degree were selected respectively from the three plants of arbor, shrub and herb for evaluation. According to the weights shown in Table 3, the comprehensive scores were finally obtained (Table 5).

Table 5. Rankings of three plants (arbors, shrubs and herbs)

\begin{tabular}{c|c|c|c|c|c}
\hline Arbor name & Score & Shrub name & Score & Herbs & Score \\
\hline Grid wood & 4.392 & Chinese wolfberry & 4.885 & Cricket grass & 4.772 \\
Rag leaf & 4.251 & Bush clovers & 4.764 & Field spinning & 4.544 \\
White cicada & 4.107 & Wild jujube & 4.652 & Dandelion & 4.346 \\
Juglans mandshurica & 4.029 & Patrinia & 4.498 & Duchesnea indica & 4.207 \\
Pu Shu & 4.004 & Lygodium microphyllum & 4.442 & Black jujube & 4.156 \\
Acer mon & 3.989 & Three white grass & 4.299 & Bletilla striata & 4.056 \\
Seven leaf lotuses & 3.974 & Centella asiatica & 4.094 & White Ginger Lily & 4.036 \\
Tilia amurense & 3.981 & Vitex negundo & 4.091 & Madder & 4.028 \\
Wood butterfly & 3.910 & Leptopus chinensis & 3.905 & Kerosene & 3.905 \\
Pistacia chinensis Bunge & 3.917 & Crabgrass & 3.513 & Light bamboo leaves & 3.759 \\
\hline
\end{tabular}

It can be seen from Table 5 that the top 3 plants in the arbors are: Grid wood, Rag leaf, White cicada; the top 3 in the shrub plants are: Chinese wolfberry, Bush clovers, Wild jujube; the top 3 of herbs are: Cricket grass, Field spinning, and dandelion.

Based on the principle of "sustainable development" and "ecological priority", it is necessary to first select plants that are easy to cultivate, adaptable, and easy to promote, and give priority to the five plants with higher scores in Table 5 as garden species and green resources, in order to continuously enrich the diversity of plants.

\section{Discussion}

The relationship between plant species distribution and population density is shown in Figure 3, and the relationship between plant species distribution and cultivated land area is shown in Figure 4. The 10 regions in the figure represent People's Park, Binjiang Leisure Park, Nanhu Park, Chaoyang Square, Cuihu New City, Mingxiu Community, Zhenning Cuifeng Community, Minzu Avenue, Chaoyang Road and University Road.

Figure 3 shows that the population density is negatively correlated with the distribution of plant species, and the region with smaller population density is richer in plant diversity, indicating that human activities directly affect the distribution of plant species, such as logging directly destroying plant species, land clearing, etc.

Figure 4 shows that the area of cultivated land is negatively correlated with the distribution of plant species, and the area with larger cultivated land area is richer in plant diversity, indicating that the area with high forest coverage has a certain protective effect on the diversity of plant species due to the small artificial disturbance.

Therefore, in order to ensure the sustainable development of plant diversity, the following countermeasures were proposed:

(1) In the planting area, the plant species needs should be selected according to local conditions such as local soil, climate, and water quality etc.; 
(2) When introducing new varieties, more emphasis needs to be put on species adaptability and pest control, so as to ensure that new species can adapt well to local natural ecosystems;

(3) It is necessary to achieve the proper management and maintenance of plants, and establish a scientific management system. In particular, the education and guidance should be strengthened to protect plant diversity.

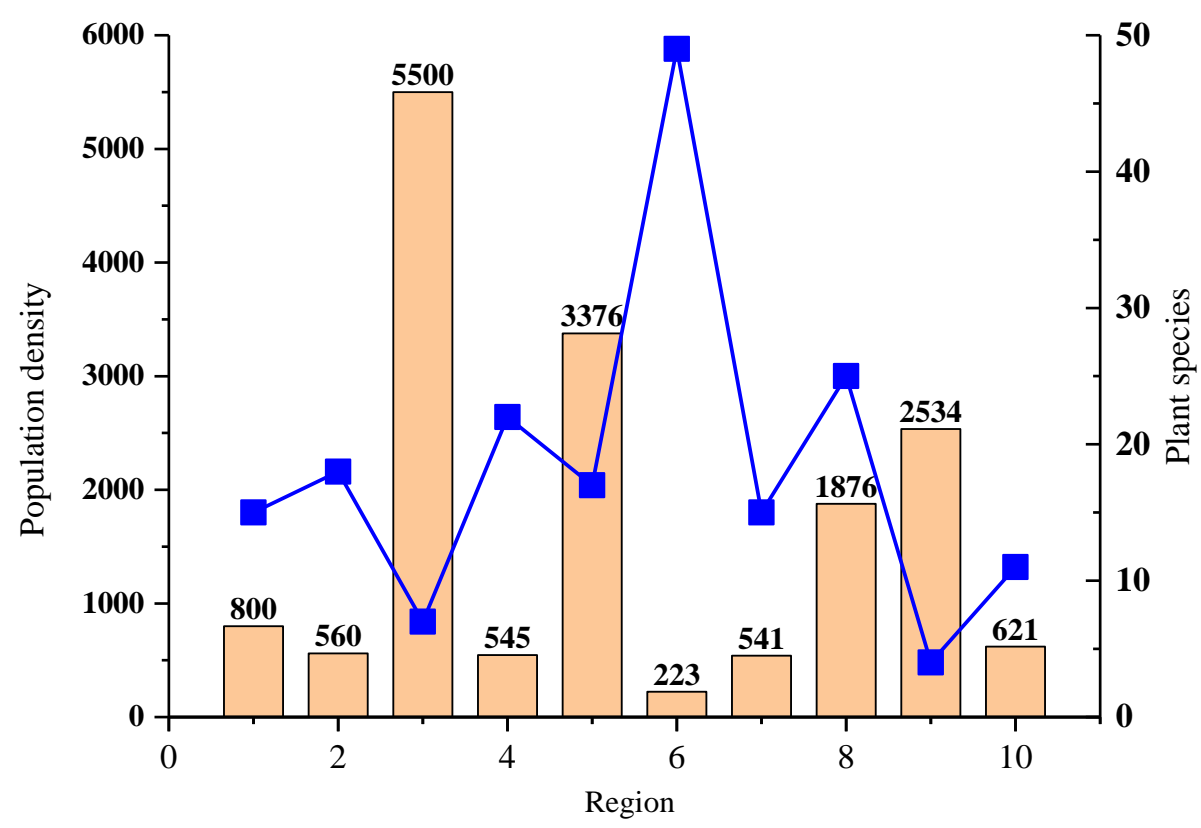

Figure 3. The relationship between plant species distribution and population density in each region

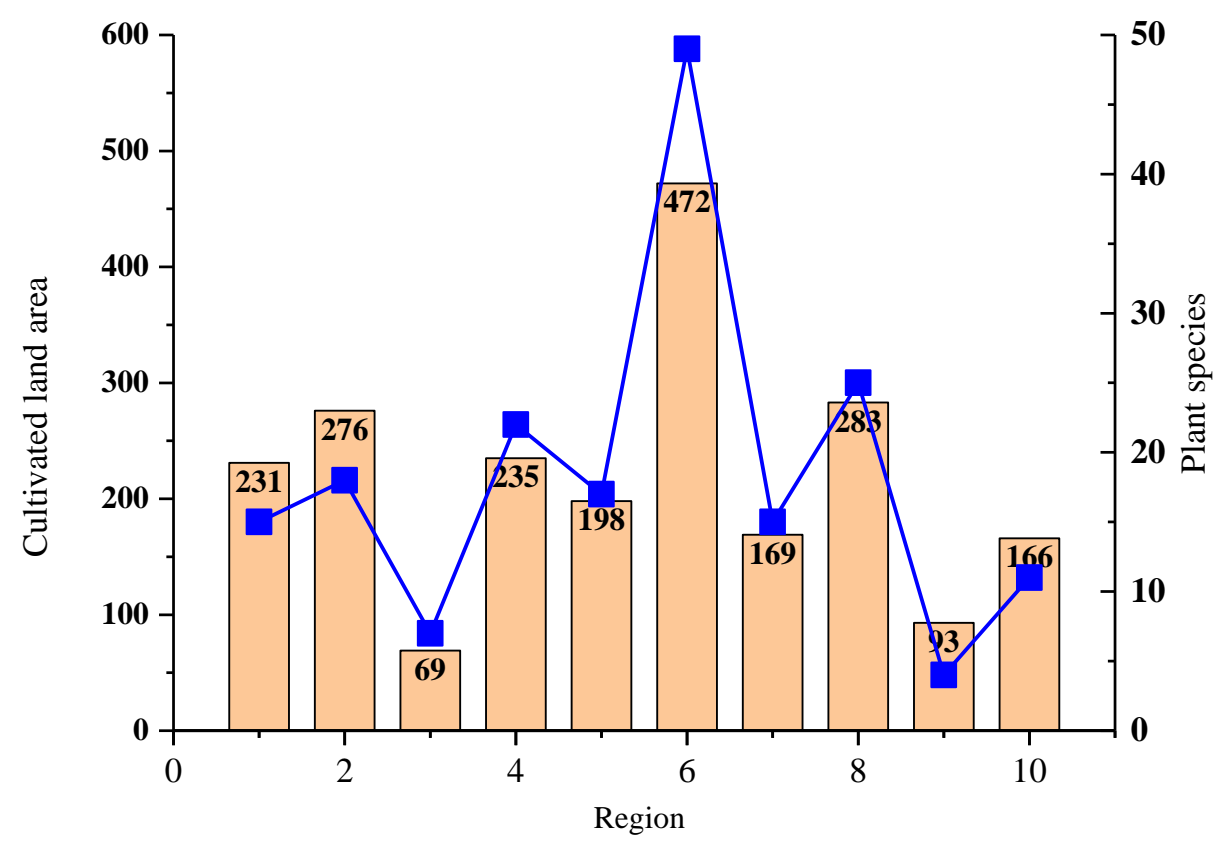

Figure 4. The relationship between plant species distribution and cultivated land area in each region 
The result analyses of this study were based on data from the one-year Nanning plant diversity survey. These data are currently the most comprehensive, widely, and convincing among the plant diversity surveys in Nanning. Through related analysis, the overall situation of different species of plants in Nanning was obtained, and the key distribution areas of alien invasive plants in Nanning were proposed, which provide the main scientific basis for the plant protection in Nanning and invasive plants prevention (Huangfu et al., 2019).

\section{Conclusion}

This paper studies the impact pf urban development on plant diversity. The main conclusions are as follows:

(1) An evaluation system on the impact of urban evolution on plant diversity was established, to solve the related impact evaluation problem of plant diversity;

(2) An integrated evaluation system consisting of five evaluation indicators of plant diversity from the perspectives, namely, species richness, species diversity, species evenness, species importance and population diversity, and three layers: target layer, criteria layer and alternative layer (biological characteristics, ecological performance and greening combined effect) were established; AHP method was used determine the weight of each index;

(3) Taking a city as an example, the plant diversity in the urban evolution process was assessed. The assessment results can provide an important scientific basis for the protection of urban biodiversity and the sustainable development of ecosystems.

In the comparative analysis of the diversity for plants, only the data in each unit sample of the same type of green space was used for comprehensive analysis, rather than the overall information of the same type of green land such as its number of species. In the subsequent study, it is a problem worthy of further discussion on how to use this information for comprehensive evaluation.

\section{REFERENCES}

[1] Anstead, J. A., Burd, J. D., Shufran, K. A. (2003): Over-summering and biotypic diversity of schizaphis graminum (homoptera: aphididae) populations on noncultivated grass hosts. - Environmental Entomology 32(3): 662-667.

[2] Breton, J., Bart-Delabesse, E., Biligui, S., Carbone, A., Seiller, X., Okome-Nkoumou, M. (2007): New highly divergent rrna sequence among biodiverse genotypes of Enterocytozoon bieneusi strains isolated from humans in Gabon and Cameroon. - Journal of Clinical Microbiology 45(8): 2580-2589.

[3] Burd, J. D., Porter, D. R. (2006): Biotypic diversity in greenbug (Hemiptera: Aphididae): characterizing new virulence and host associations. - Journal of Economic Entomology 99(3): 959-965.

[4] Crawford, M. H., Goldstein, E. (2010): Demography and evolution of an urban ethnic community: Polish Hill, Pittsburgh. - American Journal of Physical Anthropology 43(1): $133-140$.

[5] Gamfeldt, L., Lefcheck, J. S., Byrnes, J. E. K., Cardinale, B. J., Duffy, J. E., Griffin, J. N. (2015): Marine biodiversity and ecosystem functioning: what's known and what's next? Oikos 124(3): 252-265. 
[6] Huangfu, C., Hui, D., Qi, X., Li, K. (2019): Plant interactions modulate root litter decomposition and negative plant-soil feedback with an invasive plant. - Plant and Soil 437(1-2): 179-194.

[7] Hunter, P. (2007): The human impact on biological diversity. How species adapt to urban challenges sheds light on evolution and provides clues about conservation. - Embo Reports 8(4): 316-318.

[8] Karmaker, S., Ruhi, F. Y., Mallick, U. K. (2018): Mathematical analysis of a model on guava for biological pest control. - Mathematical Modelling of Engineering Problems 5(4): 427-440.

[9] Kaushal, S. S., Mcdowell, W. H., Wollheim, W. M. (2014): Tracking evolution of urban biogeochemical cycles: past, present, and future. - Biogeochemistry 121(1): 1-21.

[10] Lavorel, G. (2002): Predicting changes in community composition and ecosystem functioning from plant traits: revisiting the holy grail. - Functional Ecology 16(5): 545556.

[11] Loreau, M. (2001): Biodiversity and ecosystem functioning: current knowledge and future challenges. - Science 294(5543): 804-808.

[12] Lubbe, S. J., Di, B. M., Broderick, P., Chandler, I., Houlston, R. S. (2012): Comprehensive evaluation of the impact of 14 genetic variants on colorectal cancer phenotype and risk. - American Journal of Epidemiology 175(1): 1-10.

[13] Miki, T. (2009): A new graphical model for untangling complex relationships among environment, biodiversity, and ecosystem functioning. - Ecological Research 24(4): 937941.

[14] Olofson, K. F. G., Andersson, P. U., Hallquist, M., Ljungstr, M. E., Tang, L., Chen, D. (2009): Urban aerosol evolution and particle formation during wintertime temperature inversions. - Atmospheric Environment 43(2): 340-346.

[15] Reiss, J., Bridle, J., Montoya, J., Woodward, G. (2009): Emerging horizons in biodiversity and ecosystem functioning research. - Trends in Ecology \& Evolution 24(9): 505-514.

[16] Sun, Q., Tan, J., Xu, Y. (2010): An ERDAS image processing method for retrieving lst and describing urban heat evolution: a case study in the pearl river delta region in South China. - Environmental Earth Sciences 59(5): 1047-1055.

[17] Symstad, A. J., Chapin, F. S., Wall, D. H., Gross, K. L., Huenneke, L. F., Mittelbach, G. G. (2003): Long-term and large-scale perspectives on the relationship between biodiversity and ecosystem functioning. - Bioscience 53(1): 89-98.

[18] Tscharntke, T., Klein, A. M., Kruess, A., Steffan-Dewenter, I., Thies, C. (2005): Landscape perspectives on agricultural intensification and biodiversity - ecosystem service management. - Ecology Letters 8(8): 857-874.

[19] Weiland, A. A., Peairs, F. B., Randolph, T. L., Rudolph, J. B., Haley, S. D., Puterka, G. J. (2008): Biotypic diversity in Colorado Russian wheat aphid (Hemiptera: Aphididae) populations. - Journal of Economic Entomology 101(2): 569-574. 